\title{
Regional Oil Extraction and Consumption: A Simple Production Model for the Next 35 years Part I
}

\author{
Michael Dittmar ${ }^{1}$
}

Received: 10 March 2016/Accepted: 12 July 2016/Published online: 11 August 2016

(C) Springer International Publishing Switzerland 2016

\begin{abstract}
The growing conflicts in and about oil-exporting regions and speculations about volatile oil prices during the last decade have renewed the public interest in predictions for the near future oil production and consumption. Unfortunately, studies from only 10 years ago, which tried to forecast the oil production during the next 20-30 years, failed to make accurate predictions for today's global oil production and consumption. Forecasts using economic growth scenarios overestimated the actual oil-equivalent liquid production, while models which tried to estimate the maximum future conventional and unconventional oil production/year, using official and public country reserve data and/or private oil industry oil reserve databases, often underestimated the current conventional oil production in some larger oil-producing countries. In this paper, a new approach to model the maximal future regional and thus global oil production (part I) and the consequences for the regional oil consumption (part II) during the next decades is proposed. Our analysis of the regional oil production data during past decades shows that, in contrast to periods when production was growing and growth rates varied greatly from one country to another, remarkable similarities are found during the plateau and decline periods of different countries. As a result, we propose to model the oil production decline phase in all oil-producing regions with a universal decline function which assumes that a few years with a stable production will be followed by about 5 years with a $3 \% / y e a r$ decline and $6 \% / y e a r$ afterwards. This plateau and decline function was found to describe accurately the oil production of the past 15 years from Western
\end{abstract}

\footnotetext{
Michael Dittmar

Michael.Dittmar@cern.ch

1 Institute of Particle Physics, ETH, 8093 Zurich, Switzerland
}

Europe (EU+Norway), Mexico and Indonesia. Following this model, the particular production phase of each major oil-producing country and region is determined essentially only from the recent past oil production data. Accordingly, we find that the conventional oil production in all regions, outside of the Middle East OPEC countries, will start the $3 \% / y e a r$ decline phase between the years 2015 and 2020. Using these data, the model is then used to predict the production from all major oil-producing countries, regions and continents up to the year 2050. The limited regional and global potential to compensate this decline with unconventional oil and oil-equivalents is also presented.

Keywords After the oil peak $\cdot$ Regional oil production and consumption

\section{Introduction: Modelling the Future Oil Production}

It is difficult to imagine a modern industrialised way of life and the globalised economy without oil. For distances from a few tens to thousands of kilometre, oil is the ideal energy career for the transport of people and all kinds of consumer goods, including nuclear power plants, windmills and photovoltaics. Oil is also essential for the functioning of today's cities and megacities, which cannot be fed and maintained without an oil-based globalised industrialised agriculture and the subsequent transport of the produced food.

Despite huge scientific and technological efforts, combined with the strong wish to reduce the oil dependence of the rich and highly industrialised countries during the last 30-40 years, no realistic alternatives have been found so far. To the contrary, the growing interdependence of the global economy, based on the cheap oil-based transport 
system, only increased this oil dependence. Within the scientific community, it is generally accepted that oil is a finite resource and that the future global production and consumption must eventually decline. A relation between exploitable oil resources and the maximal possible production curve, a bell-shaped curve, was introduced in 1956 by the geologist and geophysicist Hubbert (1956).

One should thus expect that the future crude oil production possibilities and its relations with the known and yet-to-be-found exploitable oil resources should be among the most important academic research topics. However, with a few exceptions, most of the available research articles about the current and future exploitable oil reserves are not coming from academic and university researchers, but more from private energy companies and country-related energy ministries. The reason might be understood, for example, from the absence of good resource data and the missing transparency about the privately or state owned known oil fields. Keeping this missing reserve transparency and the resulting systematic unknowns about the future oil extraction in mind, one finds that essentially two different types of modelling for the future oil production and consumption exist.

The first type of forecasts are the ones from government agencies or transnational oil companies, which are inspired by political and economical regional and global ideas about the expected future demand growth. ${ }^{1}$ Examples are the annual World Energy Outlooks (WEO) from the IEA, the International Energy Agency of the OECD countries, the EIA, the Energy Information Agency of the US government, or the regular energy outlooks from oil companies such as BP. One finds that those global studies from the past decade(s) assumed that the remaining conventional and unconventional oil reserves would be cheap enough to allow economic growth trends observed during previous decades to continue. For example, the 2001 (WEO 2001) version of the annual energy outlook from the IEA imagined that global oil production and consumption would continue to grow at least to the year 2020 by about $2 \% /$ year. Accordingly, those economically-inspired models assumed that reserves are sufficient to guarantee that the global consumption of oil and oil-equivalent liquids will grow from about $80 \mathrm{mbd}$ (million barrel per day) around the year 2000 to about $105 \mathrm{mbd}$ in the year 2015 and further to $115 \mathrm{mbd}$ by 2020 . Such production and consumption growth was assumed to be possible with a relatively stable oil price of $<30$ dollar/barrel. The reality was very different as the oil price increased steadily to about

\footnotetext{
${ }^{1}$ See (1) the yearly IEA World Energy Outlook at http://www. worldenergyoutlook.org, (2) the EIA International Energy Outlook at http://www.eia.gov/forecasts/ieo/ and (3) the BP Energy Outlook at http://www.bp.com/en/global/corporate/energy-economics/energyoutlook-2035.html.
}

100 dollar/barrel in 2007/8. During the 2008 global economic crisis and during the following years, the oil price fluctuated between 50 and 100 dollars/barrel, about a factor of 2 to 4 higher than predicted. Using the August 2015 IEA estimate, ${ }^{2}$ the 2015 oil-equivalent production and consumption is estimated to be about $93-94 \mathrm{mbd}$, corresponding to an increase of about $13 \mathrm{mbd}$ with respect to the year 2000. This is a factor of two lower than the one from the WEO 2001 report, where an increase of $25 \mathrm{mbd}$ by 2015 was predicted.

Instead of trying to understand and change the underlying wrong assumptions, subsequent economic-based forecasts simply reduced the annual consumption growth rate and extended the forecast period. For example, the global production and consumption of all oil-equivalent liquids for the year 2020 decreased from $115 \mathrm{mbd}$ (WEO 2001) to about $109 \mathrm{mbd}$ (WEO 2006) and $96 \mathrm{mbd}$ in the (WEO 2015) report. It is obvious that the methods used by these economically-inspired models did not lead to reliable forecasts beyond a few years.

The second type of forecasting uses a natural sciencebased approach. Here it is tried to determine the future oil extraction possibilities using the regional and globally known and different assumptions about the yet-to-be-found oil reserves and future technological capabilities to extract them. Some of those studies are based on the publicly available best known believed to be exploitable reserves for every country as summarised, for example, by the EIA ${ }^{3}$ while others use in addition data from the oil industry. ${ }^{4}$ Unfortunately, those presumably far more accurate and detailed reserve data are not freely available. The reservebased approach for predicting the future oil extraction has just to combine some educated guesswork and assumptions about the realistically remaining exploitable oil reserves and the evolution of future extraction technologies.

Those geophysical-inspired approaches result essentially always in estimates about the maximum possible global annual oil peak production followed by the subsequent declining production. For example, the oil geologists Campbell and Laherrère estimated in their 1998 Scientific American article, "The End of Cheap Oil" Campbell and Laherrère (1998), that the global crude oil production would reach a maximum with a production of about $71 \mathrm{mbd}$ (26 giga barrel of oil per year) around the year 2005. After 2005 , the production would decline by $2-3 \%$

\footnotetext{
2 The monthly IEA oil reports can be found at the IEA website https://www.iea.org/oilmarketreport/reports/2015/0815/.

3 The oil and oil-equivalent production and consumption numbers from the past decades and the different countries can be found at the EIA oil production database http://www.eia.gov/cfapps/ipdbproject/ IEDIndex $3 . \mathrm{cfm}$ ?tid $=5 \&$ pid $=57 \&$ aid $=6 \#$.

${ }^{4}$ For a private (payable) oil database, see, for example, IHS at https:// www.ihs.com/products/oil-gas-analytics-forecasting.html.
} 
per year, corresponding to a production of about $60 \mathrm{mbd}$ by 2015. This 1998 publication was based on the uncertain public official and some private reserve estimates from oil companies about regional oil reserves. The authors corrected some of the data with their re-evaluation of some of these numbers and made some assumptions about possible additional reserves, using the oil field discovery trends from the past decades.

Many more such reserve-based regional and global production forecasts ${ }^{5}$ were published during the next few years and essentially all of them predicted a global conventional oil production peak between 2005 and 2010, followed by a decline of a few per cent a year.

However, even if today's important contributions from unconventional oil and other oil-equivalent liquids are excluded, the global conventional oil production ${ }^{6}$ neither grew nor declined since 2005 but has remained essentially at a stable plateau of about 72 mbd (Mushalik 2015).

Large relative differences between the predicted and real production trends in both types of forecasting methods are observed for Russia and China.

For example, the production of all oil-equivalent liquids in 2014 reached about $10.5 \mathrm{mbd}$ in Russia and $4.3 \mathrm{mbd}$ in China. $^{7}$

In comparison, the ASPO 2006 study predicted production peaks around the year 2010 of about $9.2 \mathrm{mbd}$ (e.g. $13 \%$ lower) and 3.4 mbd (e.g. $21 \%$ lower) for Russia and China, respectively. For Russia, they predicted a decline around the year 2015 to about $7 \mathrm{mbd}$, which is about $30 \%$ too low. For China, they predicted about $2 \mathrm{mbd}$ which is more than a factor of 2 too lower than the actual 2014 production. It is interesting to note that the economicallyinspired IEA (WEO 2001) global growth scenario predicted similar production peaks and declines for Russia and China.

In contrast, very different production forecasts were made for the Middle East OPEC countries. The IEA essentially always expected that the production in this region would increase by about $10 \%$ every 5 years, while the resource-based models predicted essentially a flat production between 2010 and 2020. In reality, the production has up to now increased, but only half as much as predicted

\footnotetext{
5 See oil production forecasts from the ASPO newsletters and especially between 2001 and 2006 at https://aspoireland.wordpress. com/newsletter/newsletters-pdf/. Many more regional and global forecasts can be found at http://www.theoildrum.com.

${ }^{6}$ In the following, we use the crude and condensate oil production numbers as given by the EIA database minus the contribution coming from unconventional tight oil and tar sands in North America.

7 These and other oil production and reserve data for different countries and regions are taken from the EIA database. More information about particular countries is taken from the more detailed descriptions of the oil production from the EIA at http://www.eia.gov/ beta/international/rankings/\#? prodact=53-1\&cy=2014.
}

by the IEA. Despite these shortcomings, it is important to acknowledge that the 1998 paper from Campbell and Laherrère (1998) and the subsequent resource-based studies predicted essentially correctly the end of cheap oil (below 30 dollars/barrel) and the steeply declining oil production in Western Europe.

Perhaps one might also accept the explanation that the shortcomings of the resource-based forecasts originate from the inaccurate oil reserve data and not from the method used. Unfortunately, one cannot expect significantly improved accuracies of those exploitable oil reserve databases. Furthermore, the publicly available oil reserve data as regularly published from the EIA or from companies such as BP are a badly defined mixture between the remaining, or original in place, exploitable conventional oil with different qualities, unconventional tight oil and oil from tar sands. Furthermore, these reserves are also often biased, either upwards or downwards, by the political and economic interests of oil companies and entire countries.

Despite these uncertainties, it is undoubted that oil is a finite fossil fuel, and that oil production, depending on the remaining regional reserves, must eventually decline in all regions of the planet. The question addressed in this paper is thus whether the past 5-10 years of regional oil production data, as presented by the EIA, believed to be rather accurate and easily available, can be used to model and thus predict the future regional oil production with perhaps an improved predictive power.

In the following, such a new and simple model, which is essentially based only on the past production data from different countries, is proposed. We first ("A Simple Model to Forecast the Oil Production Over the Next Decades" section) introduce our basic model assumptions using the past conventional oil production data from Western Europe (EU+Norway), Indonesia and Mexico. Using this model, the maximal possible regional conventional oil production is estimated for all oil-producing region and continents and up to the year 2050 ("Western Europe", "RUSSIA and Other FSU Countries", "Asia/Oceania”, "Africa”, "South and Central America", "North America", "The Persian Gulf OPEC countries" section).

It is important to consider that the real production might be considerable lower, as production interruptions because of wars or because of regional or global economic recessions during the coming years and decades are not included in this approach. Possible reasons for a steeper production decline are discussed, for example, in more detail in reference Tverberg (2016).

The prospects of substituting unconventional oil, and supposedly oil-equivalent liquids, for crude oil are discussed in "Production of Unconventional Oil and OilEquivalent Liquids" section. In "Predicting 2014 Production Using the 2000 to 2005 Data" section, the model is 
tested using the observed oil production trend between the years 2000 and 2005 to make predictions for 2014 which can be compared with the actual 2014 crude oil production. In "A Comparison with Other 2015 Models" section, we compare the results from our global oil production forecast for the next decades with the ones from other estimates.

In "Near-Term Consequences for the Large Oil Importers" section, the consequences of the modelled near future oil and oil-equivalent production for the different consumer regions around the year 2020 are discussed. A more detailed analysis of the future import and export possibilities and some of the possible consequences for the energy return on investment of the different larger producer and consumer countries and regions will be presented in a subsequent paper.

\section{A Simple Model to Forecast the Oil Production Over the Next Decades}

As presented in the introduction, the officially presented public or private oil reserve data do not exist in a transparent scientific format which would include some information about the crude oil quality and the related uncertainties and difficulties in exploiting the claimed reserves. As a consequence, the accuracy to predict the future maximal conventional and unconventional oil production using real or presumed oil reserves alone can only be as accurate as the reserve data. The examples from the North Sea (UK and Norway), considered perhaps to be the most transparent past reserve data, and from Mexico can serve as a confirmation of this problem.

For example, the crude oil reserves of the UK and Norway in 1983 were given as $14 \mathrm{~Gb}$ [giga barrel of oil $\left(=10^{9}\right.$ barrel) $]$ and $6.8 \mathrm{~Gb}$, respectively. However, when calculating the original in place reserves from combining: (a) the total oil extraction between 1984 and 2013, which corresponds, according to the EIA data, to 21.4 (UK) and $24 \mathrm{~Gb}$ (Norway) with (b) the remaining reserves at the end of 2013 are 3.1 (UK) and $5.4 \mathrm{~Gb}$ (Norway) one finds the resulting 1983 reserves as about 25 (UK) and $30 \mathrm{~Gb}$ (Norway), which is much larger than originally claimed.

For Mexico, the EIA database shows that a total of $23 \mathrm{~Gb}$ had been extracted between 1994 and 2013 and $10 \mathrm{~Gb}$ remain for extraction. Consequently, the reserves, given as $51 \mathrm{~Gb}$ in 1993 , were overestimated by $18 \mathrm{~Gb}$.

It follows that estimates for the future oil extraction from these three countries, based only on the officially reserves given in 1983 and 1993, would not have resulted in a prediction anywhere near the real and declining production during the last 5-10 years.

Knowing that the reserve data for many other countries are even less transparent than in the examples above, it appears impossible to make accurate oil production forecasts based on official reserve data. Perhaps these problems explain already why the past predictions failed to describe the actual oil production for Russia, China and the Middle East. Furthermore, as improvements in exploration technologies and the associated monetary exploration costs are somewhat a secret of the oil companies, it is also clear that the future production from unconventional oil and oilequivalent liquids is also very uncertain.

We are thus presenting in the following a different approach, which tries to use essentially only the trends observed during the past 5-10 years of regional oil production data, using the EIA data, to predict the future regional and global conventional oil production.

Additionally, it is assumed that the regional oil production depends not only on the amount of exploitable oil reserves in the territory, but also on the possibility of transporting the oil from the producing region to the user region and this under the most profitable conditions for the private or public owner of the field and for the exploiting companies. Furthermore, we assume that the highest profits can be made somewhere between these conditions:

- The oil production in a particular region rises as quickly as technically possible to a maximum, which can be maintained only for a few years, because the overall production must decline once new fields cannot be opened as quickly as the older fields decline. The exploitation of the oil fields in the North Sea, mainly operated from the UK and Norway, is a good example for such regions.

- The oil reserves in the country are huge, and sufficiently large enough profits can be made from exports, even if the oil production is limited for political or economic reasons below the possible maximum. The oil production in Saudi Arabia and its oil-rich neighbouring countries can be considered as examples.

- Production can also be limited, if the theoretically producible oil in a given region cannot be exported easily because neither there are no pipelines nor does a sufficiently large oil tanker-based transport capacity exist. The oil production in a landlocked country such as Kazakhstan is an example for this case.

Furthermore, we assume that the consequence of finite exploitable oil reserves, within a given field and region, will eventually result in a steeply and on average universally declining oil production. Support for such a universal decline comes from the IEA studies in the World Energy outlooks WEO 2008 and WEO 2013, which concluded that older oil fields eventually all decline on average by about $6 \%$ /year. The authors of the IEA study (2013) have found this number from a total of more than 1600 larger oil fields from all around the planet. 
In short, our model is based on the idea that the plateau production years will be followed by a steeply declining oil production, as observed in the UK, Norway, Indonesia and Mexico and described below. We presume that this declining production profile can be used as a universal decline curve for all ageing conventional oil extraction regions of the planet.

\section{The Declining Oil Extraction in Western Europe, Mexico and Indonesia}

Crude oil production in Western Europe (EU plus Norway) increased steeply during the last decade of the twentieth century. The production reached a plateau-like maximum of around $6.2 \mathrm{mbd}$ and for about 5 years and production started to decline around the year 2002. Since 2004, and despite much higher oil prices, the extraction of oil from all Western European oil fields combined began to decline steeply. During 2014, the crude oil production was reduced to $2.87 \mathrm{mbd}$, less than half of the amount reached during the production plateau.

Similar oil production declines are documented for Mexico and Indonesia. During the last decade of the twentieth century, the crude oil production in Indonesia reached a plateau value of around $1.5 \mathrm{mbd}$ and declined by a factor 2 during the last 14 years to $0.79 \mathrm{mbd}$ (2014). Mexico reached a production plateau of about $3.4 \mathrm{mbd}$ during the years 2001-2006, from were it declined to only 2.5 mbd during 2014.

In order to simplify the comparison between these countries and regions, the yearly crude oil production is normalised to their average plateau production values and the years are shifted by +3 years for Indonesia and -4 years for Mexico, such that the last plateau year is matched for all countries. The resulting production curves are shown in Fig. 1. While the growth period shows significant differences, when looking over a period of 5-10 years during the decline period, the observed decline appears to be rather similar for the three regions. In addition, one can also observe that, during some smaller time intervals, a flattening in the decline is possible. Presumably this can be understood due to the opening of likely less profitable smaller oil fields.

In order to describe the decline period, a simple model is proposed which postulates that a few plateau years will be followed by a 5 year period with a $3 \%$ year average decline, followed by a $6 \% /$ per year decline. The resulting curve (dotted in Fig. 1) provides an overall good description of the steeply declining oil extraction trends observed from Western Europe, Mexico and Indonesia. An annual production decline of $6 \pm 1 \%$ implies that, at the end of ten years, production will be only $54 \pm 6 \%$ of what it was at the beginning of those 10 years. In order to use this model to estimate the future production in different regions, the last plateau year needs to be defined. In order to minimise annual fluctuations, it is proposed to use the available average production data from the last 3 years as a starting point and the production trend will be defined from the previous 3 years. Thus, according to the EIA database, the conventional oil production for Western Europe in 2012, 2013 and 2014 was 3.0, 2.83 and $2.87 \mathrm{mbd}$, respectively. When averaging the production during these 3 years one obtains the 2013* annual production of $2.9 \mathrm{mbd}(1.06 \mathrm{~Gb})$. Using the $6 \% / y e a r$ decline, the production in 2020 is modelled as $1.9 \mathrm{mbd}(0.69 \mathrm{~Gb})$. If instead one would choose a single year between 2012 and 2014 as the starting year, the production would have declined to 1.9 mbd sometime between 2019 and 2021 . Accordingly, it is proposed to use this \pm 1 year as the model uncertainty if the country/region is already in the $6 \% / y e a r$ decline phase. If the country or region is in the plateau or $-3 \%$ decline phase, the uncertainties must be slightly larger, and for simplicity, it is guesstimated that the uncertainty is twice as large, corresponding to $\pm 2-3$ years.

Using the $6 \%$ annual decline rate and the 2013* average production of $1.06 \mathrm{~Gb}$, the future annual crude oil production for 2020, 2030 and 2050 is estimated as being about $0.69,0.37$ and $0.11 \mathrm{~Gb}$, respectively. Assuming an exponential decline, the production will obviously never become exactly zero. However, one can use the total future production according to this decline model and estimate the year when today's claimed reserves will be terminated. Assuming the $6 \%$ annual production decline, and starting with the 2013* annual extraction from Western Europe, Mexico and Indonesia of 1.06, 0.93 and $0.30 \mathrm{~Gb}$, respectively, one finds that their official crude oil reserves (end of 2013) of 12.8, 11.1 and $3.7 \mathrm{~Gb}$ will all be exhausted around the year 2035 .

Assuming, however, that new findings or reserve revisions, due to improved extraction technology, will increase the 2013 reserves by about $30 \%$, the predictions from this decline model might become extendable up to the year 2050.

Our simple model can therefore also be used to transform the usually quoted static reserves, the lifetime with a constant production, into a more realistic dynamic lifetime with a declining annual production. For example, if the remaining reserves are given with a static lifetime of 10 years and the actual production declines by $6 \% / y e a r$, the declining production can continue for about 20 years. Alternatively, if the yet-to-be-found reserves would increase the current oil reserves by about $30 \%$, the $6 \% /$ year production decline period could be extended from the 20 year limit to about 35 years. In a similar way, realistic reserves can be estimated for countries and regions which are declining by $6 \% / y e a r$ since some years. Assuming that 
Fig. 1 Crude oil extraction curves from three declining countries and regions. The data are normalised to each average peak production result (the average from the years close to the maximum). The peak year for Mexico and Indonesia was 2006 and 1999, respectively. Their data are shifted such that the "peak year" matches with the 2002 peak year from Western Europe. The dotted curve is the prediction from the model, which assumes the plateau ends with an annual production decline of $3 \% / y e a r$ for 5 years followed by a $6 \% /$ year decline

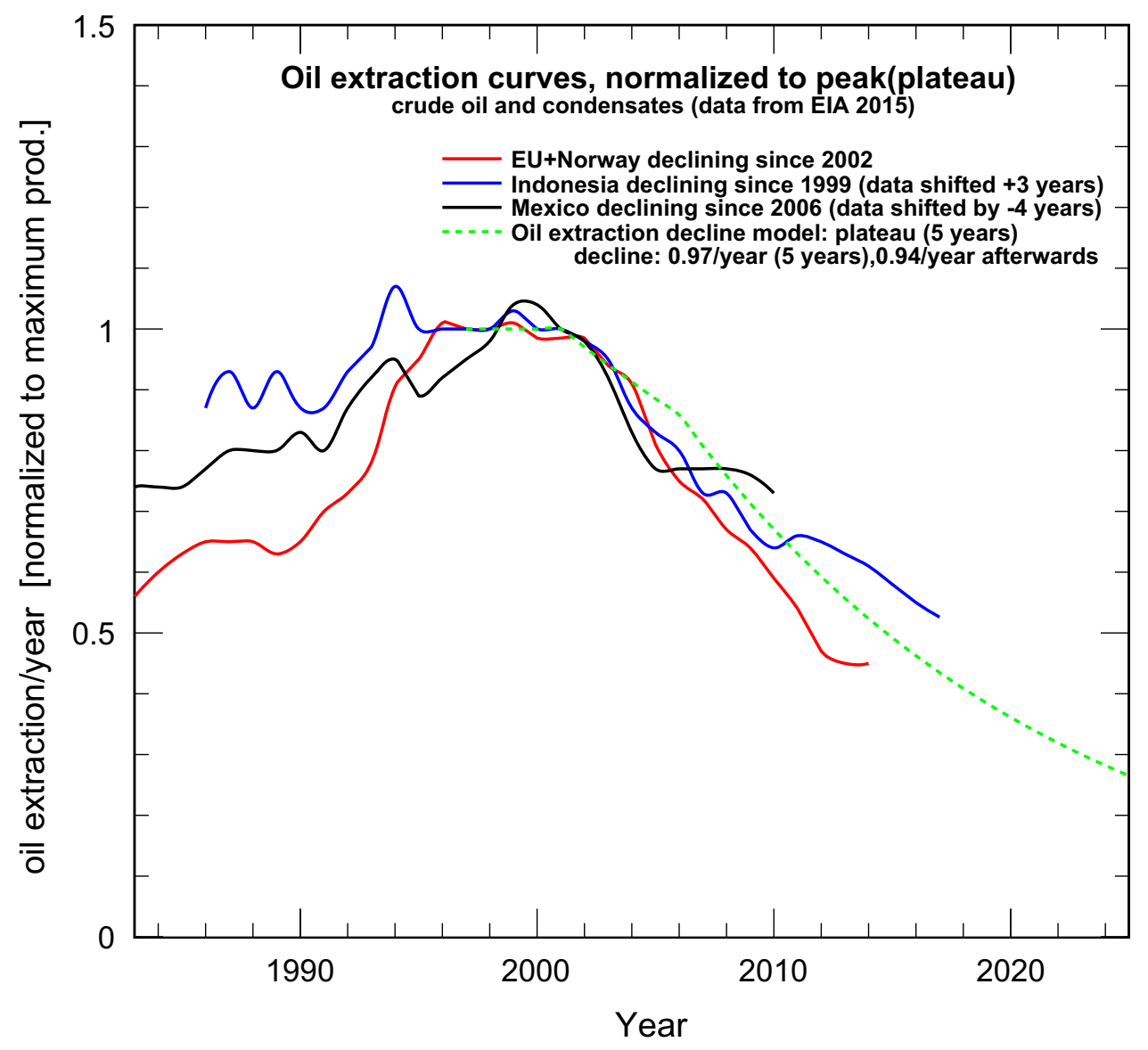

those decline rates can be sustained roughly for the next 25 years, an annual extraction of about $1 \mathrm{~Gb}$ (or $2.74 \mathrm{mbd}$ ) corresponds to exploitable in place reserves of about $13 \mathrm{~Gb}$. Our simple model, which uses nothing more than production trends from the past few years, leads thus also to a good approximation of remaining reserves.

Alternatively, the consistency of the presented static reserves could be determined by comparing the estimated potentially possible production phase with the recent production trend in every region. For example,

- Static reserves of less than 15 years mean that the steep annual production decline of $6 \%$ per year has started or will be imminent;

- Static reserves between 15 and 20 years mean that the 5 year period with an annual production decline of about $3 \%$ has began or will start now;

- Static reserves between 20 and 25 years mean that the plateau production can continue for at most 5 years and

- Static reserves larger than 25-30 years mean that the plateau production can either be extended for many more years or that there is a real possibility to increase production during the next few years.

\section{Regional Oil Extraction, the Next 35 years}

Following the ideas, which lead to the simple model in the previous section, the EIA conventional crude oil production data and officially claimed reserves from the last 5-10 years from all major producing countries, regions and continents are used to:

- Compare the actual production and the internal consumption with the reserves,

- determine the actual production phase according to our model, separated in growth, plateau and the 3 or $6 \%$ decline phase,

- and apply our model to estimate the future oil production up to the year 2050 in a country or region and discuss the consequences for future crude oil exports.

Tables 1 and 2 summarise the officially given conventional and unconventional oil past production and reserve data and the results from our simple model for their corresponding future oil production for the years 2020 and 2030. The corresponding predictions for the next 35 years and essentially all regions and continents are shown in Figs. 2 and 3. 
Table 1 Conventional crude oil reserves and production numbers from the EIA (2014)

\begin{tabular}{|c|c|c|c|c|}
\hline Region & $\begin{array}{l}\text { Reserves } \\
\text { (Gb) } 2014\end{array}$ & $\begin{array}{l}\text { Production (mbd year) } \\
2010^{*} / 2013^{*}\end{array}$ & $\begin{array}{l}\text { Production phase } 2015 \\
\text { (\%/year) }\end{array}$ & $\begin{array}{l}\text { Modelled production } \\
\text { (mbd year) 2020/2030 }\end{array}$ \\
\hline Norway & 6 & $2.12 / 1.57$ & $-6 \%$ & $1.02 / 0.55$ \\
\hline EU & 6 & $1.77 / 1.33$ & $-6 \%$ & $0.86 / 0.46$ \\
\hline Western Russia & $\sim 60$ & $9.4 / 9.3$ & $-3 \%$ & $7.5 / 4.0$ \\
\hline Far Eastern Russia & $\sim 20$ & $0.3 / 0.7$ & $\geq+10 \%$ & $1.6 / 1.4$ \\
\hline Azerbaijan & 7 & $1.0 / 0.88$ & $-3 \%$ & $0.63 / 0.34$ \\
\hline Kazakhstan & 30 & $1.51 / 1.57$ & $\sim+1 \%$ & $1.8 / 1.4$ \\
\hline China & 24 & $4.0 / 4.15$ & Plateau & $3.6 / 1.9$ \\
\hline India & 5.5 & $0.73 / 0.78$ & Plateau & $0.78 / 0.5$ \\
\hline other Asia/Oceania & 15.5 & $3.01 / 2.76$ & $-3 \%$ & $1.9 / 1.0$ \\
\hline Libya* & 48 & $1.3 / 0.9$ & Plateau $^{+}$ & $1.5 / 1.5$ \\
\hline Algeria & 12 & $1.56 / 1.47$ & $-6 \%$ & $1.0 / 0.53$ \\
\hline Angola & 9 & $1.84 / 1.78$ & $-3 \%$ & $1.35 / 0.73$ \\
\hline Nigeria & 37 & $2.41 / 2.44$ & Plateau & $2.5 / 1.6$ \\
\hline Other Africa & 22 & $2.23 / 1.9$ & Plateau $^{+}$ & $2 / 1.2$ \\
\hline Saudi Arabia & 268 & $8.9 / 9.75$ & Plateau $^{+}$ & $10 \pm 1$ \\
\hline Other OPEC Persian Gulf & 524 & $12.9 / 13.4$ & Plateau $^{+}$ & $14 \pm 1.5$ \\
\hline Brazil & 15 & $2.04 / 2.11$ & $\sim 1 \%$ & $1.8 / 1.0$ \\
\hline Venezuela* & 80 & $2.47 / 2.5$ & Plateau $^{+}$ & $2.5 / 1.6+0.9$ \\
\hline Other South/Central Am. & 13 & $2.2 / 2.33$ & "Plateau" & $2.1 / 1.35$ \\
\hline USA (convent.) & 23 & $4.6 / 4.3$ & $-3 \%$ & $3.7 / 2.0$ \\
\hline USA (tight) & $14^{*}$ & $0.9 / 3.2$ & $\geq 10 \%$ & $4.5 / 4.5$ \\
\hline Canada(convent.) & $6^{*}$ & $1.23 / 1.12$ & $-3 \%$ & $0.85 / 0.5$ \\
\hline Sands+tight & 167 & $1.5 / 2.2$ & $\geq 10 \%$ & $3 / 3$ \\
\hline Mexico & 10 & $2.62 / 2.54$ & $-6 \%$ & $1.6 / 0.9$ \\
\hline
\end{tabular}

The average oil and condensates production from the years* 2009-2011 and 2012-2014 are separated for conventional and the tight oil and tar sand production. The production forecast for 2020 and 2030 is the result obtained from our model. The Plateau ${ }^{+}$stands for regions where the past years oil production was limited by political and economic conditions. For Venezuela, it is assumed that the decline will be compensated by some heavy oil production starting during the next decade

\section{Western Europe}

The declining crude oil production and consumption in Western Europe (EU+Norway+Switzerland) has been used to develop the current model and many details are given in "A Simple Model to Forecast the Oil Production Over the Next Decades" section. In addition to those arguments presented already, it is important to consider the fact that oil production in essentially all Western European countries is in decline and that all countries, excluding Norway, import a large fraction of the consumed oil.

Following this model, the overall conventional oil production in Western Europe is predicted to decrease from 2.9 (2014) to $1.9 \mathrm{mbd}$ (2020), 1.0 (2030), 0.55 (2040) and $<0.3 \mathrm{mbd}$ around the year 2050 .

As it is tried to model the future production and consumption in each region, the crude oil production in Norway, the only exporting country in Western Europe, is of particular relevance to its oil-importing neighbours.
Conventional oil production in Norway has declined from 2.95 (2004) to $1.57 \mathrm{mbd}$ (2014), and $<80 \%$ of this oil was exported in 2014 to the neighbouring EU countries.

Following our model, ${ }^{8}$ the conventional oil production in Norway will fall to $1 \mathrm{mbd}$ by 2020 . Assuming that the internal oil consumption will stay at today's level and that the production from the new large Sverdrup oil field will not be happening according to the plans, the exports to the EU will decline accordingly. During 2014, $41 \%$ of the exported oil ${ }^{9}$ was sent to the UK, $27 \%$ to the Netherlands

\footnotetext{
8 The future production from the Johan Sverdrup oil field, discovered in 2011, might lead to an additional production of perhaps $0.55 \mathrm{mbd}$ from 2019 onwards (Campbell 2015).

However, this potential production is currently excluded in our estimate.

${ }^{9}$ Details about the Norwegian oil production and exports are summarised at the EIA website under https://www.eia.gov/beta/ international/analysis.cfm?iso=NOR.
} 
Table 2 EIA Production data for 2010 and 2014 and our guesstimated global and regional upper production limits for 2020 and 2030 for the various types of oil and oil-equivalents

\begin{tabular}{lllll}
\hline Region & $\begin{array}{l}\text { Production } \\
(\text { mbd) 2010 }\end{array}$ & $\begin{array}{l}\text { Production } \\
\text { (mbd/year) 2014 }\end{array}$ & $\begin{array}{l}\text { Production } \\
\text { phase 2015 }\end{array}$ & $\begin{array}{l}\text { Modelled production } \\
\text { (mbd) 2020 and 2030 }\end{array}$ \\
\hline World (oil-equivalent) & 85.7 & 90.7 & $\sim 1 \%$ & $\leq 90 / 77$ \\
World (convent. oil) & 72.4 & 71 & Plateau & $\leq 66 / 50$ \\
World (NGL) & 8.9 & 10.1 & $\sim 3 \%$ & $13 / 13$ \\
World (tight+tar sands) & 2.3 & 6.8 & $\geq 10 \%$ & $\leq 8 / 11$ \\
World (other liquids) & 2.2 & 2.7 & $\sim 5 \%$ & $\leq 3 / 3$ \\
USA (NGL) & 2.1 & 3.0 & $\geq 10 \%$ & $4 / 4$ \\
Middle East (NGL) & 3.0 & 3.1 & Plateau & $4 / 4$ \\
Other (NGL) & 3.8 & 4.0 & $2 \%$ & $5 / 5$ \\
USA (tight) & 0.8 & 4.2 & $\geq 10 \%$ & $5.0 / 5.0$ \\
Canada (tight) & 0 & 0.4 & "Starting" & $0.5 / 0.5$ \\
Other (tight) & 0 & 0 & $\geq 10 \%$ & $2.0 / 2.0$ \\
Canada (tar sands) & 1.5 & 2.2 & "Starting" & $2.5 / 2.5$ \\
Venezuela (oil sands) & 0 & 0 & $0 / 1$ \\
\hline
\end{tabular}

Total global production uncertainties are dominated by the $\pm 2.5 \mathrm{mbd}$ attributed to the future production in the Persian Gulf region. The so-called refinery gains are not included in these numbers, but are estimated by the EIA as being globally about 2.5 mbd for 2014

Fig. 2 Conventional crude oil production data from 2000 to 2014 (full lines) and the modelled future production up to the year 2050 (dotted lines), for all major oil-producing regions and continents, outside the Middle East

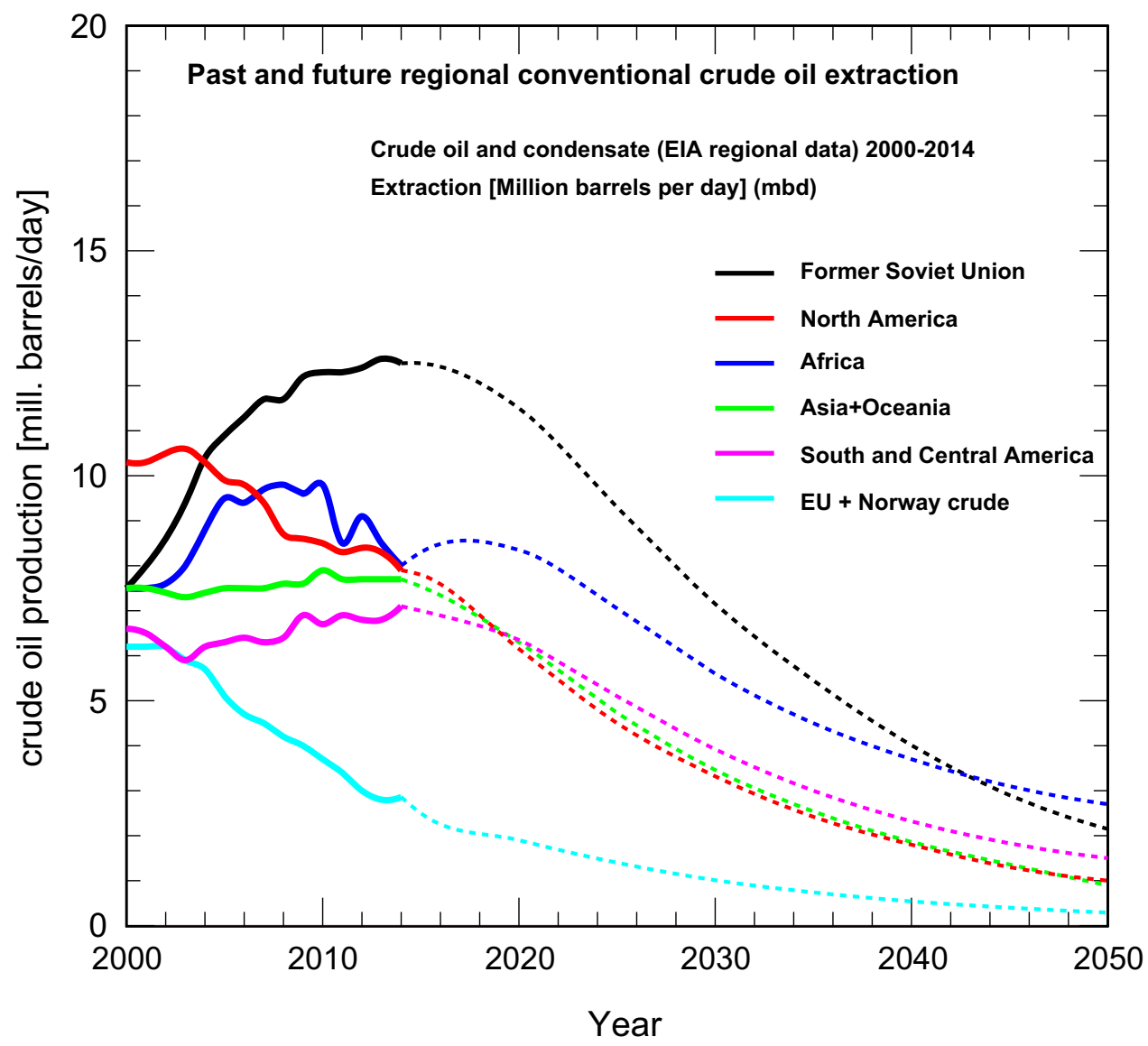

and $12 \%$ to Germany. So it is especially important for the UK and the Netherlands to find other oil-exporting sources as quickly as they can. As will become clear in the next subsection, neither Russia nor the other oil-exporting countries from the FSU will be able to replace the missing million barrels of oil during the next decades. 
Fig. 3 Global conventional crude oil, unconventional oil and oil-equivalent production data from 2000 to 2014 and projections from 2020 to 2050 as identified in the key at the top of the chart

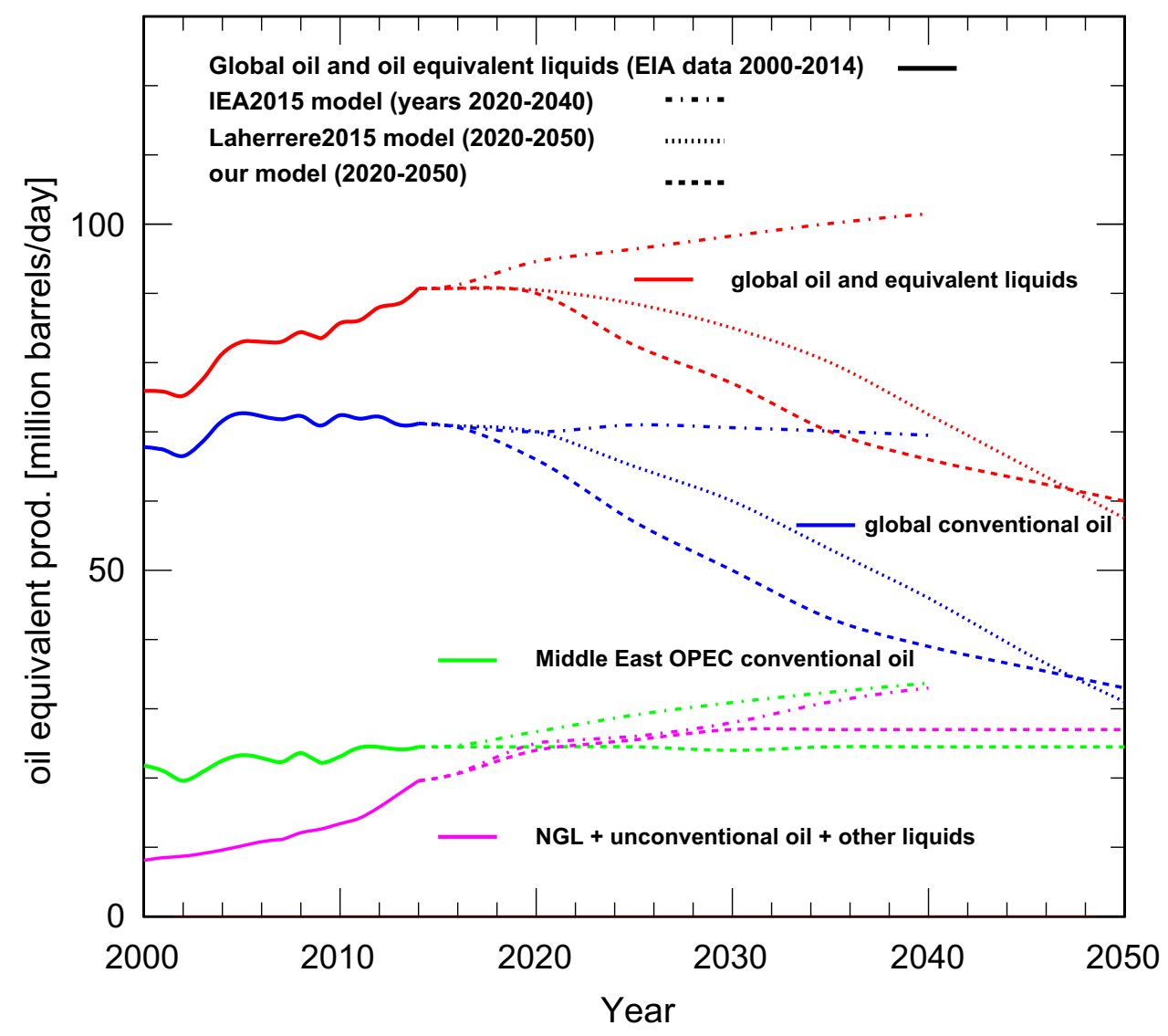

\section{RUSSIA and Other FSU Countries}

The three Former Soviet Union countries with substantial oil production and reserves are Russia, Kazakhstan and Azerbaijan. During 2013/14, about 6 mbd of crude oil were exported from these countries, mainly from and through Russia to Western Europe. ${ }^{10}$

During the last years, the total production in Russia reached a plateau of $10 \mathrm{mbd}$ (2014). However, it is important to realise that about $90 \%$ of this oil is produced from relatively large oil fields in the western parts of Russia and of Western Siberia. Most of these fields are in little populated regions of Western Siberia and are exploited since decades. From there the oil is transported through a vast pipeline system to the European part of Russia and from there to Western Europe. ${ }^{11}$

The other $10 \%$ of the produced crude oil comes from relatively new explorations. Most of the new explorations are in Eastern Siberia, and this oil will be transported

\footnotetext{
${ }^{10}$ More details about the oil production and exports in Russia and the other FSU countries can be found at the EIA website and in the 2015 BP Statistical World Energy review.

${ }^{11}$ See Henderson 2012 at https://www.hhs.se/contentassets/e5fcf384 94dc4d2c840fa572f0339be9/5-james-henderson and http://www. oxfordenergy.org/author/james-henderson/.
}

through existing and planned pipelines to China and other Asian countries. Subtracting the growing production in Eastern Siberia from Russia's total production, it seems that the first decline phase (3\%/year) in the Western parts of Russia has began already or is imminent. This seems to be confirmed by the latest statements from the Russian oil company Lukoil and also from a recent IEA report. ${ }^{12}$

Consequently, the year 2015 will be assumed here to be the beginning of the $3 \%$ year decline phase in Western Russia and Western Siberia, followed by the $6 \% / y e a r$ decline from 2020 onwards. The oil production from Eastern Siberia, if production goes more or less according to plans, should rise from about $1 \mathrm{mbd}$ in 2014 to $1.6 \mathrm{mbd}$ by 2020 (Henderson 2012). It is assumed that production will stay at this plateau for 5 years to 2025 and will start to decline by $3 \% / y e a r$ to 2030 and $6 \%$ year afterwards. Combining our model with these assumptions, one finds that the production in 2020 will be about $7.5 \mathrm{mbd}$ from

\footnotetext{
12 Statements about the possible declining oil production especially in the Western parts of Russia and Siberia were made recently by Leonid Fedun, vice-president of Lukoil. According to http://uk. reuters.com/article/russia-crisis-lukoil-idUKL5N0W537K20150303 he said the drop could amount to as much as $0.8 \mathrm{mbd}$ by the end of 2016. Similar conclusions seem to be obtained from a detailed IEA report (2014) about energy in Russia (section 6) http://www.iea.org/ publications/freepublications/publication/Russia_2014.
} 
Western Russia and 1.6 mbd in Eastern Siberia. Calculated accordingly, the total Russian crude production in 2030 will be about $5.4 \mathrm{mbd}$.

The official Russian reserves increased, according to the EIA database, from 60 (2012) to $80 \mathrm{~Gb}$ (2013). Assuming that this increase came mainly from the inclusion of the new findings in Eastern Siberia, the Western and far Eastern Russia reserves at the end of 2013 are guessed as 60 and $20 \mathrm{~Gb}$, respectively. Following the modelled oil extraction profile, about $6 \mathrm{~Gb}$ in Western Russia and $5.5 \mathrm{~Gb}$ in Eastern Siberia would remain after 2050.

The crude production in Azerbaijan rose quickly from 0.5 to 1 mbd between 2005 and 2011, but declined by $15 \%$ during the last 3 years to $0.85 \mathrm{mbd}$ in 2014 . It is assumed that the $3 \%$ decline phase is ongoing and will continue to 2016. Afterwards, the production will decline by $6 \% / y e a r$ and the production in 2020 and 2030 is modelled to be 0.63 and $0.34 \mathrm{mbd}$, respectively. Accordingly, the current reserves, given as $7 \mathrm{~Gb}$, would be reduced to about $2 \mathrm{~Gb}$ by the year 2050 .

The official reserves of the landlocked country Kazakhstan are given as $30 \mathrm{~Gb}$. Between 2010 and 2014, crude oil production grew by about $7 \%$. New and planned oil explorations and pipelines are all found in the eastern parts and it thus seems logical to assume that the additional oil will all be exported to China. For the older oil fields, mostly connected through pipelines to the Russian infrastructure, it is assumed that they will start the decline during the next 5 years. Combining this with some continued growth in the eastern parts, a plateau production at around 1.8 mbd will be reached between 2018 and 2023. After that and applying our model, the production will decline by $3 \% / y e a r$ to 2028 and $6 \%$ year afterwards. It is thus estimated that the production in 2020 will be $1.8 \mathrm{mbd}$ from where it will decline to $1.4 \mathrm{mbd}$ by 2030 . According to this modelled production profile, the remaining reserves around 2050 would be about $15 \mathrm{~Gb}$. One might conclude either that today's reserves of Kazakhstan are overestimated or that additional production and export capacity of up to 2 mbd might be developed during the next decades. Considering the geographical location and the growing importance of China in this region, it seems most likely that any new and expensive pipeline structures would deliver this additional oil to China.

Combining the internal oil consumption in the FSU countries, given as 4.4 mbd during 2014, it is assumed that the internal consumption increase observed during the past years might continue for a few more years to at least to $4.5 \mathrm{mbd}$ in the year 2020. Given increase in the FSU's consumption and the decrease in its production, oil available for export to Western Europe will decline from $6 \mathrm{mbd}$ in the year 2014 to about 4 mbd (2020) and will essentially be terminated around the year 2030 .

\section{Asia/Oceania}

The remaining crude oil reserves in the Asia and Oceania region, where almost half of the world population lives, are relatively small and are given by the EIA as $45 \mathrm{~Gb}$ at the beginning of 2014. The overall production stayed roughly constant during the last 10 years and about $2.5 \mathrm{~Gb}$ of crude oil was produced during the year 2014. During the same period, the annual consumption in this region increased by about $30 \%$ from 7.5 to about $10 \mathrm{~Gb}(27 \mathrm{mbd})$. Most of this imported oil originates from the Middle East OPEC countries and is transported by large ships that carry up to $3 \mathrm{mb}$.

Slightly more than half of the estimated remaining reserves and of the current production in this area is associated with China. The crude oil production in China grew during the first decade of the twentieth century, but appears to have reached the plateau production phase. The future production for China is modelled at a plateau value of 4.2 mbd until 2015, followed by 5 years with $3 \% / y e a r$ decline and by $6 \% /$ year afterwards. Production would decrease accordingly to about $3.6 \mathrm{mbd}$ in 2020 and $1.9 \mathrm{mbd}$ in 2030. Following this extraction model, China's official reserves, $24 \mathrm{~Gb}$, would be terminated around the year 2050.

India's reserves at the beginning of 2014 are given as $5.5 \mathrm{~Gb}$ and production over the past decade was rather stable at about $0.7-0.8 \mathrm{mbd}$. This is still far below the relatively small internal consumption of $3.7 \mathrm{mbd}(1.35 \mathrm{~Gb} /$ year). It is assumed that this production plateau can be maintained to 2020 , and will decline by $3 \% / y e a r$ to 2025 and by $6 \% / y e a r$ afterwards. According to the modelled future production, India's reserves will be exhausted around the year 2050 .

Combining the other Asian and Oceanic oil-producing countries, mainly Indonesia, Malaysia, Australia, Thailand and Vietnam, one observes that their production since 2009 declined by about $13 \%$ and thus almost by $3 \% / y e a r$. It is assumed that the $6 \%$ decline period starts in 2016 . Accordingly, the production will decline from $2.76 \mathrm{mbd}$ (2013) to 1.9 and 1.0 mbd by 2020 and 2030, respectively. With reserves of about $15.5 \mathrm{~Gb}$ (end of 2013) and our modelled production, the reserves are expected to be terminated between 2045 and 2050.

\section{Africa}

Oil production perspectives on this huge continent, with a population of about 1 billion people, can be comfortably divided into North Africa and the sub-Saharan Africa. The total oil reserves of Africa at the beginning of 2014, given by the EIA, are $127 \mathrm{~Gb}$. About $83 \%$ of these oil reserves are found in four countries: Libya $(48 \mathrm{~Gb})$, Nigeria 
(37 Gb), Angola (9 Gb) and Algeria (12 Gb). About $76 \%$ of the African oil in 2014 was produced by these four countries. With an overall production of $8 \mathrm{mbd}$ and an almost negligible per capita oil consumption of 0.6 litre per day, $>50 \%$ of the produced oil in 2014 was, according to the 2015 BP report, exported to Western Europe ( $2.8 \mathrm{mbd})$, China $(1.3 \mathrm{mbd})$, India $(0.6 \mathrm{mbd})$ and North America (0.6 mbd).

\section{North Africa}

The oil production in Libya, with its small population, is heavily affected by the "aftershocks" of the recent war against this country. The 2014 production was $0.5 \mathrm{mbd}$, about $1 / 3$ of the production before the war. Even if the presumably huge and high-quality crude reserves of $48 \mathrm{~Gb}$ would be largely exaggerated and without further wars, it should be possible to increase the oil production at least to the pre-war level of $1.5 \mathrm{mbd}(0.55 \mathrm{~Gb} /$ year $)$ and maintain it at that level for many decades. It is assumed that around the years 2020 and in the following decades the production will reach the pre-war production of around $1.5 \mathrm{mbd}$.

Algeria, a country with almost 40 million people and with a very young population, had managed to increase the oil production between the year 2000 and 2008 by about $40 \%$ to $1.7 \mathrm{mbd}$. During the following years, the production declined by almost $20 \%$ to $1.4 \mathrm{mbd}$ in 2014. At least since 2004, the reserves are given as $12 \mathrm{~Gb}$ and were not changed according to the yearly extraction of about $0.5 \mathrm{~Gb}$. The remaining reserves can thus be guessed to be at least $5 \mathrm{~Gb}$ smaller than officially given. The decline during the last years corresponds to an average of about $3 \% / y e a r$. Accordingly, it is expected that the yearly $6 \% /$ year decline phase starts during 2015. The resulting annual oil production is thus modelled to be about $1 \mathrm{mbd}(0.3 \mathrm{~Gb} /$ year) and $0.5 \mathrm{mbd}$ in 2020 and 2030, respectively. Depending on the actual true reserves, the declining production might last until 2050. Following this production decline and assuming that the actual internal consumption, about $0.4 \mathrm{mbd}$ in 2014, will stay at the current level as long as possible, oil exports from this country, mainly to France, will end around the year 2030.

The third North African country, with some small oil production is Egypt. The production in 2014 was about $0.5 \mathrm{mbd}$, slightly smaller than in 2009 when almost $0.6 \mathrm{mbd}$ were produced. As this decline is probably more related to the unstable political situation in the country, it is assumed that the current production can be maintained at the current level of $0.5 \mathrm{mbd}$ until 2020 followed by the $3 \% / y e a r$ decline phase (2021-2025) and the 6\%/year decline phase in 2026 . The resulting modelled oil production will be about $0.5 \mathrm{mbd}$ in 2020 and $0.32 \mathrm{mbd}$ in 2030. The total production up to 2050 would add up to about $4 \mathrm{~Gb}$. This matches with the reserve estimate given as $3.6(\mathrm{BP})$ and $4.4 \mathrm{~Gb}$ (EIA).

Considering the long-term historical cultural relations between all countries in North Africa, and especially the common border between the highly populated Egypt and the small population of Libya, one can imagine that the Libyan oil will eventually be directly shared with the people in Egypt and possibly also with the people in the other North African countries.

\section{Sub-Saharan Africa}

With $2.4 \mathrm{mbd}$, Nigeria is currently the largest oil producer in Africa and almost $90 \%$ of this oil is exported. With several new production areas under preparation, the production could potentially be increased during the next decade to $>3$ mbd. However, civil war and other political instabilities within the country resulted in large production fluctuations and major delays of new projects. If the remaining reserves in 2015 are indeed $37 \mathrm{~Gb}$, and if the civil war-like problems for the production can be avoided during the next decades, it might be possible to increase the production to perhaps $3.5 \mathrm{mbd}$ and remain at this level for several decades.

As in many other countries, it is unclear whether the currently reported reserve number represents the actual reserves or the original in place reserves. Assuming that the reported $37 \mathrm{~Gb}$ refers to original in place reserves, the total production between 1980 and 2014, about $25 \mathrm{~Gb}$, needs to be taken into account for the future production estimates. Under this extreme scenario, the remaining reserves would be more like $12 \mathrm{~Gb}$, and the current production could only be maintained for another decade. In the absence of better data, it is assumed that the current plateau-like production of about $2.5 \mathrm{mbd}$ will be maintained until 2020. Afterwards, the production is modelled to start the $3 \% / y e a r$ decline followed by $6 \% / y e a r$ from 2025 onwards. The total extraction from 2015 to 2050 is modelled to be about $17 \mathrm{~Gb}$.

The other important oil producer and oil-exporting country is Angola. The production in 2014 was $1.74 \mathrm{mbd}$, about $5 \%$ smaller than the average production between 2009 and 2013. The years 2014-2018 are thus assumed to correspond to the $3 \% / y e a r$ decline period. Accordingly, the modelled 2020 and 2030 production will be about 1.4 and $0.7 \mathrm{mbd}$, respectively. The total modelled oil production until 2050 is thus predicted to be about $10 \mathrm{~Gb}$, which matches the reserve numbers given by BP of $12.7 \mathrm{~Gb}$ and the EIA of $9 \mathrm{~Gb}$.

The production from all the other smaller producing sub-Saharan African countries in 2014 was 1.4 mbd. This significant decrease from the $1.7 \mathrm{mbd}$ produced in 2010 might be explained by the very unstable political and 
economic situation in many African countries. For Egypt, it is assumed that the current production can be kept stable until 2020, and that the $3 \%$ /year decline will start in 2021. The total production is modelled to be 1.5 and $0.9 \mathrm{mbd}$ in 2020 and 2030, respectively. Their combined total production to 2050 corresponds to about $12 \mathrm{~Gb}$, which is slightly smaller than the totalled estimated reserves of $15.2(\mathrm{BP})$ and 16.6 (EIA).

\section{South and Central America}

Overall, only Brazil, Venezuela and Ecuador are known to have considerable oil reserves. However, a large fraction of these reserves, are very difficult to exploit. Examples are the unconventional oil sands in Venezuela (about 220 of the $298 \mathrm{~Gb}$ ), the recently found very deep-sea oil in Brazil (about 10 of the total $15 \mathrm{~Gb}$ ) and the oil in the biodiversityrich and partially protected Amazon region of Ecuador (total $8.8 \mathrm{~Gb}$ ). The reserves of all other countries in South and Central America combined are given as 7.2 Gb.

During the last 5 years, the crude oil production in South and Central America increased by $7 \%$ from 6.7 (2010) to $7.1 \mathrm{mbd}$ (2014). The consumption of all liquids during this period increased by $14 \%$ to about $7.1 \mathrm{mbd}$ in 2014. Most of this production increase came from Brazil (from 2.06 to $2.26 \mathrm{mbd}$ ) and Colombia (0.79 to $0.99 \mathrm{mbd}$ ). Brazil, despite its production increase, remains a large importer with an annual average of about $1 \mathrm{mbd}$. Due to the relatively low internal per capita oil consumption, Venezuela, Columbia and Ecuador consumed internally only a small fraction of the produced oil. The 2014 exports are reported as 1.9, 0.7 and $0.3 \mathrm{mbd}$, respectively.

Focusing first on Venezuela, it is important to notice that today's oil production, about $2.5 \mathrm{mbd}$, is $30 \%$ lower than during the peak years around 1970 and between 1995 and 2000. The supposed huge reserves of this OPEC country are known to have very low quality and the numbers appear to be very political as large upward changes were reported during the last decades. Between 1980 and 2010, the claimed conventional reserves increased from 18 to $59 \mathrm{~Gb}$ (1990), 73 (2000) and 99 Gb (2010). The potential oil sand reserves of $220 \mathrm{~Gb}$ were added to the total reserves during the next years and the official reserves increased further to 211 (2011) and to $298 \mathrm{~Gb}$ (2013). The exploration prospects of these unconventional reserves are discussed in "Production of Unconventional Oil and Oil-Equivalent Liquids" section.

The more conventional reserves are claimed to be about $80 \mathrm{~Gb}$, almost as large as the reserves associated with Russia. Even if these $80 \mathrm{~Gb}$ are considered to represent the original in place oil reserves around the year 1980, about $45 \mathrm{~Gb}$ reserves should remain as about $35 \mathrm{~Gb}$ have been extracted during the last 35 years. Even such reduced reserves would be roughly twice as large as the ones in the USA and China. One would thus expect that the daily production could perhaps be increased to $3.5-4 \mathrm{mbd}$ and remain at this level for some decades. In the absence of convincing reserve data and following the plateau-like production during the last decade, it is assumed that the current annual oil production of Venezuela, about $2.5 \mathrm{mbd}$ $(0.91 \mathrm{~Gb} /$ year), can potentially be maintained for several decades. If this production would be maintained to 2050, a total of about $30 \mathrm{~Gb}$ would be extracted which is still smaller than the claimed remaining or original in place reserves. Perhaps it is more realistic to assume that the remaining reserves are much smaller than claimed and that the production will start to decline by about $3 \%$ /year during the next 5-10 years. It is thus expected that the production will start to decline during the next decade and will decline from 2020 onwards by $3 \%$ /year and will reach about 1.6 mbd (2030). Adding a possible production from the huge oil sand reserves (see "Production of Unconventional Oil and Oil-Equivalent Liquids" section) it is assumed that the overall oil production might approximatively remain until 2050 at today's level of $2.5 \mathrm{mbd}$.

The situation for Brazil looks even more difficult to predict, as the access to about 2/3 of the claimed reserves appears to be technologically extremely difficult. Since it now appears unlikely that the country's deep-sea oil eld exploration will begin any time soon, ${ }^{13}$ it is assumed that the plateau value has been reached already and that the $3 \%$ year decline will start in 2016. Accordingly, the modelled production is $1.8 \mathrm{mbd}$ by 2020 and $1 \mathrm{mbd}$ in 2030. This production decline scenario results in a total production of about $7.5 \mathrm{~Gb}$ by 2025 and would still require that some substantial fraction of the deep-sea oil reserves, about $10 \mathrm{~Gb}$, can be successfully exploited during the next decade.

The future oil production in Ecuador, with official reserves of $8 \mathrm{~Gb}$, depends critically on biodiversity protection measures which might be taken in the Amazon region. As it seems unlikely that any clear decision will be made during the next few years, it is assumed that the current annual production of about $0.5 \mathrm{mbd}(0.2 \mathrm{~Gb} / \mathrm{year})$ can be maintained during the next decades.

Combining all other producing countries in South and Central America, a rather constant crude oil production of about $1.8 \mathrm{mbd}$ was observed during the last 5 years. Accordingly, one expects that the $3 \% / y e a r$ production decline period will begin in 2016 and followed by $6 \%$ /year from 2021 onwards. The modelled production is estimated

\footnotetext{
${ }^{13}$ For the recent problems with the Brazilian Petrobras Oil Company see, for example, the 30 December 2015 Article "Scandal-hit Petrobras faces new challenge" in the "Financial Times" http:// www.ft.com/int1/cms/s/0/9daaa982-a9a0-11e5-843e-626928909745. html\#axzz3yGQb5bey.
} 
to be 1.57 (2020) and $0.85 \mathrm{mbd}$ (2030). The resulting total production up to 2030 would be about $7.5 \mathrm{~Gb}$, which exceeds the current claimed reserves of $5.2 \mathrm{~Gb}$.

Combining the above production numbers, it is expected that the total conventional oil production within South and Central America will decrease from the current level of about 7 to $6.3 \mathrm{mbd}$ around 2020 and $4.8 \mathrm{mbd}$ (2030). Given the uncertain prospects of Brazil's deep-sea oil fields, and given the lack of clarity regarding the ratio of conventional to unconventional oil reserves in Venezuela, the estimated future maximum oil production in South and Central America is probably overestimated.

\section{North America}

In this section, only conventional crude oil production, current and future, in the USA, Canada and Mexico is discussed. The situation and prospects with unconventional oil and other liquids, which increased rapidly during the past few years, especially and dominantly in the USA and Canada, are presented in detail in "Production of Unconventional Oil and Oil-Equivalent Liquids" section.

Oil production in Mexico started to decline in 2006 and has reached the average decline rate of about $6 \% / y e a r$ during the last few years. As the situation in this country was used to develop the future production model, more details are found in "Simple Model to Forecast the Oil Production Over the Next Decades" section. However, it is important to note that Mexico produced about $2.5 \mathrm{mbd}$ crude oil plus $0.3 \mathrm{mbd}$ of other liquids and consumed about 2 mbd oil-equivalents per year (about 1000 litre/capita). During past years, most of the oil exports were sent to the USA. With a roughly constant internal consumption since 2006, the exported oil has decreased steeply from about $1.7 \mathrm{mbd}$ in 2006 to $0.7 \mathrm{mbd}$ in 2014. Assuming that internal consumption during the next few years remains roughly at today's level, the current $6 \%$ year decline leads to the conclusion that by the year 2020 Mexico will essentially stop being an oil-exporting country.

After many years of declining crude oil production in the USA, the situation has changed dramatically during the last few years. Crude oil and condensate production decreased steadily from 8.6 in 1980 to $7.4 \mathrm{mbd}, 5.8$ and $5.0 \mathrm{mbd}$ in the years 1990, 2000 and 2008. Since 2008, however, the trend has changed, and production in 2014 is reported to be $8.65 \mathrm{mbd}$, which is essentially as high as 35 years ago. This production increase was possible due to the new tight (shale) oil technology, which allowed exploitation of unconventional and relatively large oil resources.

In order to model future production of conventional crude oil, the tight oil production has to be subtracted from total liquids production, just as production of other oil liquids must be. According to the EIA reference, ${ }^{14}$ one finds that the tight oil production in the USA went up from about $0.1-0.2 \mathrm{mbd}$ between the years 2000 and 2007 to 0.5 in 2008 and from there to 2.2, 3.2 and $4.2 \mathrm{mbd}$ in 2012, 2013 and 2014, respectively. Details about the future possible shale oil production and other unconventional oil resources are discussed in "Production of Unconventional Oil and Oil-Equivalent Liquids" section.

The conventional crude oil production in the USA has thus continued to decline by about 1.5 to $2 \%$ year from 8.6 (1980) to $5.7 \mathrm{mbd}$ (2000) to $5.1 \mathrm{mbd}$ (2005) to $4.7 \mathrm{mbd}$ (2010) and to $4.5 \mathrm{mbd}$ in 2014. This observed decline rate during the last decades is smaller than what would be expected from our decline model. But this smaller decline rate can be easily explained by the contributions from the recently opened off-shore oil fields in the Gulf of Mexico along with increased production in Alaska. If more new fields were to be opened, it would obviously reduce the overall production decline rate. The officially declared remaining crude oil reserves in the USA have increased from $23 \mathrm{~Gb}$ (2008), before the tight oil reserves were included, to $37 \mathrm{~Gb}$ in 2014. It appears logical to attribute about $23 \mathrm{~Gb}$ for the conventional reserves and $14 \mathrm{~Gb}$ to the exploitable tight oil reserves.

Accordingly, one observes that the current conventional oil reserves of the USA and their 2014 production data match roughly with the 2014 numbers from China, presented in "Asia/Oceania" section. Without detailed information about a possible extraction from additional offshore or arctic oil deposits, it is assumed that the already declining conventional crude oil production in the USA will start the $3 \% / y e a r$ and $6 \% / y e a r$ decline phases in 2016 and 2021, respectively. The conventional USA oil production is thus modelled as $3.7 \mathrm{mbd}$ (2020) and $2 \mathrm{mbd}$ (2030). The modelled annual conventional oil production will exceed the official reserves around the year 2040.

The conventional plus unconventional oil production in Canada is reported by the EIA as 3.3 and $3.6 \mathrm{mbd}$ in 2013 and 2014, respectively. Conventional crude oil production in Canada is obtained by subtracting, from total production, the tar sands production [2.0 (2013) and $2.2 \mathrm{mbd}(2014)$ ] and the tight oil production $[0.3$ (2013) and $0.4 \mathrm{mbd}$ (2014)]. ${ }^{15}$

It follows that the conventional oil production declined from an average of 1.23 (2009-2011) to $1.12 \mathrm{mbd}$ (2012-2014), respectively. In the absence of more detailed data, it is assumed that the 5 year $3 \% / y e a r$ decline period

\footnotetext{
14 The USA past tight oil production data can obtained from http:// www.eia.gov/forecasts/aeo/section_energyprod.cfm.

15 The tight oil and oil from tar sands production and reserve numbers for Canada are taken from http://www.eia.gov/todayine nergy/detail.cfm?id=19991 and http://www.capp.ca/publications-andstatistics/statistics/basic-statistics.
} 
goes from 2013 to 2018 followed by the $6 \%$ /year decline. The corresponding oil reserves are not given independently. However, according to the Statistical World Energy review from BP, the "tar sand reserves" are estimated as $167 \mathrm{~Gb}$. Accordingly, the conventional crude oil reserves are about $6 \mathrm{~Gb}$ and the total production would exceed these $6 \mathrm{~Gb}$ a few years after 2050.

Combining the three countries and following our model, the expected maximal possible conventional oil production will start its decline from 7.9 (2014) to $6.2 \mathrm{mbd}$ (2020) and $3.4 \mathrm{mbd}$ (2030). Adding a roughly constant production of unconventional oil from tar sands in Canada (2.5 mbd) and a total tight oil production of about $4.5 \mathrm{mbd}$ for the years 2020 and 2030, respectively (for details see "Simple Model to Forecast the Oil Production Over the Next Decades" section), the combined conventional and unconventional crude oil production from North America is estimated to decline from about $14.7 \mathrm{mbd} \mathrm{(2014)}$ to about $13 \mathrm{mbd}$ (2020) and $10 \mathrm{mbd}$ (2030).

\section{The Persian Gulf OPEC Countries}

The combined oil production of the six Persian Gulf OPEC countries-Saudi Arabia, Iraq, Iran, Kuwait, UAE and Qatar-amounted to $23.4 \mathrm{mbd}$ (about $8.5 \mathrm{~Gb} / \mathrm{year}$ ) in 2014. Their combined official crude oil reserves, either in place or originally, are given by BP and EIA as about $800 \mathrm{~Gb}$, or as roughly $61 \%$ of the global total conventional oil reserves. Even if their remaining reserves are exaggerated, and even if the roughly $230 \mathrm{~Gb}$ produced during the last 35 years should be subtracted from the estimated $800 \mathrm{~Gb}$, their combined remaining reserves are still huge.

In fact, most of these Middle East OPEC countries might have some real and some theoretical spare oil-producing capacity. Considering that it is far easier and thus cheaper for those countries to extract their oil than it is for any other region, there seems currently no reason to even consider large investments to increase the production and export capacities. Assuming that wars, like the one in 2003 when the USA and its allies attacked Iraq, can be prevented, it is expected that these six countries can keep their combined production within roughly $\pm 10 \%$ of today's level of $24 \pm 2.5 \mathrm{mbd}$ at least to the year 2050 .

\section{Production of Unconventional Oil and Oil- Equivalent Liquids}

The production of unconventional oil and oil-equivalent liquids increased steeply during the last decade, corresponding today to roughly $20 \%$ of the worlds total liquid energy consumption. The largest contribution to unconventional oil-equivalent liquids comes from "Natural Gas
Liquids" (NGLs ${ }^{16}$ ) which are a by-product of natural gas production.

It is generally accepted that the extraction of unconventional oil is technically very difficult, less energy efficient and more polluting than the extraction of conventional crude oil. In addition, the comparison is further complicated by slightly different usages of these different oil-equivalents liquids. An easy and commonly used way to estimate these differences is to compare the monetary cost of extracting conventional and unconventional oil.

However, this approach is certainly limited as the environmental costs and the political costs to extract and transport the oil safely to the consumer are difficult to calculate. It is, for example, difficult to compare the monetary costs of non-conventional oil produced in the USA with the costs of the conventional oil produced in Eastern Siberia that must be transported over very long distances. The cost of pipelines, or similar transport infrastructure, for conventional oil that must be transported long distances might thus favour more local and more expensive unconventional oil production.

The monetary oil costs for producers and consumers are even more difficult to estimate when one thinks about the problems to obtain the oil from unstable countries such as Iraq. And monetary costs are even more difficult to estimate whether one is dealing with a country where all or parts of which are war zones or potential war zones.

A fair comparison should thus also include also the "secure" production and transport cost from the production site to the refinery or buyer. In particular, the absence of pipelines or similar transport infrastructure for the usage of far away produced conventional oil might thus favour the more local and more expensive unconventional oil production and usage.

Consequently, some might argue that the costs of local tight oil and tar sand oil production are lower than the potential costs of oil imports from unstable regions such as the Middle East. Keeping these problems with unconventional oil and oil-equivalent liquids in mind, the maximum possible production perspectives, following the EIA and similar economical estimates, for the next decades are guesstimated in the following.

\section{Production of NGLs}

The largest contribution to unconventional oil-equivalent liquids comes from "Natural Gas Liquids".

According to the EIA, the NGL production increased globally from $6.4 \mathrm{mbd}$ in the year 2000 to $10.1 \mathrm{mbd}$ in

\footnotetext{
$\overline{16}$ For more details about NGLs see http://www.eia.gov/todayine nergy/detail.cfm?id=5930.
} 
2014. Significant production, with more than $1 \mathrm{mbd}$, came from the USA and Saudi Arabia with a production of 3 and $1.8 \mathrm{mbd}$, respectively. According to the estimates from the EIA, ${ }^{17}$ NGL production in the USA might further increase by $30 \%$ to a plateau of about 4 mbd between 2020 and 2040. In the absence of more data, it is assumed that NGL production in different regions will increase by a similar amount and will globally grow to a plateau value of about 13 mbd oil-equivalent between 2020 and 2030 and remain at this level until 2050.

\section{Tight Oil Production}

The extraction of unconventional oil from shale deposits in the USA and Canada increased considerably during the last 5 years. Tight (shale) oil production in the USA and Canada increased, respectively, from only 0.2 and $0.0 \mathrm{mbd}$ in 2007 to 4.2 and $0.4 \mathrm{mbd}$ in 2014. The EIA, in its 2015 Energy Outlook, foresees USA tight oil production reaching a maximum of $5.6 \mathrm{mbd}$ in 2020. From there, it is expected to decline to $4.8 \mathrm{mbd}$ in 2030 and $4.3 \mathrm{mbd}$ in 2040

According to a different study, ${ }^{18}$ USA tight oil production might increase only a little more and reach a plateau of around 5 mbd between 2020 and 2030 from where it will decline to $4 \mathrm{mbd}$ around 2040. The authors of this study estimated that global tight oil production will be at most 7.5 mbd between 2030 and 2035 and 6.5 mbd around 2040 with about $2.5 \mathrm{mbd}$ coming mainly from Argentina, Canada and Russia.

For the overall forecast model, the above numbers are used as the upper production limit and it is assumed that tight oil production in the USA and elsewhere will increase to about $5 \mathrm{mbd}$ around 2020 and about $7 \mathrm{mbd}$ after 2025 . However, it seems that the latest EIA production data indicate that tight oil production has peaked during the summer 2015 and that production will decline during the next 2 years. ${ }^{19}$ If this production decline is indeed seen during this short period, it might be more realistic to believe that the actual production during the next few years will very likely be significantly less than the modelled upper production limit.

\footnotetext{
17 The 2015 EIA estimation for the increase in the US NGL production can be found in Table A-14 at http://www.eia.gov/ forecasts/aeo/pdf/0383(2015).

18 Presentation from J. Webster (Global Oil Markets) for the future global tight oil production at the July 2014 EIA conference http:// www.eia.gov/conference/2014/pdf/presentations/webster, page 8 .

19 The EIA expects that a steep decline of the US oil production during 2016 and 2017, see the 12 January 2016 Short-Term Energy Outlook from the EIA http://www.eia.gov/forecasts/steo/report/us oil.cfm.
}

\section{Oil Production from Tar Sands, Biofuels and Coal to Liquids}

Unlike tight oil production in the USA, unconventional oil production from the tar sands in Canada has increased only slowly despite huge reserves of about $167 \mathrm{~Gb}$. It seems that production during 2013/2014 has reached a plateau around $2.2 \mathrm{mbd}$. In the light of the past growth trend, and given the latest news about severe labour layoffs in the field, ${ }^{20} \mathrm{I}$ expect that Canada's tar sand oil production might at most reach a plateau of $2.5 \mathrm{mbd}$ by 2020 and remain at that level during coming decades.

Oil production from the Venezuelan oil sands is very hard to predict. In the absence of clear data, it is assumed that this production might begin in the next few years and eventually reach $1.2 \mathrm{mbd}$ or about $50 \%$ of the Canadian oil sand production. Keeping the very uncertain political future of Venezuela in mind, it can be assumed that the country's oil sand production might do no more than stabilise their overall oil production at around $2.5 \mathrm{mbd}$ ("South and Central America" section) from the near future to 2050.

According to the EIA database, the production of bio fuels is dominated by the USA $(1.3 \mathrm{mbd})$ and Brazil $(0.55 \mathrm{mbd})$, and even when taken together with liquids from coal contributed only about $2.7 \mathrm{mbd}$ worldwide in 2014. As it seems rather unlikely that the global contribution from such fuels will change dramatically over coming decades, one can assume that the production of such liquids will remain essentially unchanged at or below $3 \mathrm{mbd}$.

\section{Predicting 2014 Production Using the 2000 to 2005 Data}

Assuming that the model described in this paper had been suggested already in 2006, the corresponding predictions for the year 2014 can be compared with the available conventional crude oil production data from the EIA for the year 2014. This is especially interesting for Russia, China and the Middle East OPEC countries where economic (IEA) and resource-based forecasts failed to describe the actual production trend.

Following the approach described at the beginning of "Regional Oil Extraction, the Next 35 years" section, one can try to use the corresponding 3 year average oil production for the years $2001 *$ and 2004* to infer the 2006 production phase and make a forecast for the year 2014 (Table 3). As can be seen, the model can be applied

\footnotetext{
${ }^{20}$ See, for example, the October 2015 article in the NYT http://www. nytimes.com/2015/10/13/business/international/oil-sands-boom-driesup-in-alberta-taking-thousands-of-jobs-with-it.html.
} 
Table 3 Average conventional oil production 2001*(2000-2002) and 2004* (2003-2005), the inferred production phase and the modelled forecast and production for 2014

\begin{tabular}{|c|c|c|c|c|}
\hline Region & $\begin{array}{l}\text { Production } \\
(\mathrm{mbd}) 2001 *\end{array}$ & $\begin{array}{l}\text { Production } \\
\text { (mbd/year) 2004* }\end{array}$ & $\begin{array}{l}\text { Production phase } \\
2006 \text { (/year) }\end{array}$ & $\begin{array}{l}\text { Modelled/production } \\
\text { production (mbd) } 2014\end{array}$ \\
\hline Persian Gulf (OPEC) & 19.5 & 21.3 & $\sim+1 \%$ & $23 / 24.3$ \\
\hline Russia & 6.9 & 8.6 & $\sim+3 \%$ & $10 / 10.1$ \\
\hline China & 3.3 & 3.5 & $\sim+3 \%$ & $4 / 4.2$ \\
\hline Western Europe & 6.4 & 6.1 & $\sim-6 \%$ & $3.3 / 2.9$ \\
\hline Russia+Azerbaijan+Kazakhstan & 8.1 & 10.2 & $\sim+5 \%$ & $12 / 12.6$ \\
\hline Asia+Oceania & 7.45 & 7.5 & $\sim$ Const & $6.7 / 7.7$ \\
\hline Africa & 7.5 & 8.75 & $\sim 2.5 \%$ & $10.3 / 8.0^{*}$ \\
\hline South America & 6.4 & 6.1 & $\sim-3 \%$ & $6.3 / 7.1$ \\
\hline North America & 10.9 & 10.4 & $\sim-1 \%$ & $7.4 / 7.9$ \\
\hline World (convent. oil) & 68 & 71 & $\sim 1 \%$ & $69 / 71$ \\
\hline
\end{tabular}

directly only for Western Europe, North America and perhaps Asia+Oceania. For the other regions, the beginning of the plateau and its length are difficult to infer because the production was growing in the other regions (see "A Simple Model to Forecast the Oil Production Over the Next Decades" section). However, as discussed in "Regional Oil Extraction, the Next 35 years" section, some political and economical factors, not free from wishful biases, can be used to estimate the end of the growth period which marks the year when our model can be used to make prediction for the year 2014.

For the Persian Gulf OPEC countries, one would expect that the recovery from the 2003 Iraq war would lead to continued growth of about $1 \% / y e a r$ during the subsequent 5-10 years and a resulting production plateau around 23-25 mbd for several subsequent decades.

For Russia, one could argue that the $3 \%$ year growth observed during those 5 years would lead production to a level close to the one that existed before the break up of the Soviet Union. Accordingly and following the proposed model, one would have most likely predicted further growth leading to a 5 year production plateau at about 10 mbd until 2015, followed by the $3 \% / y e a r$ and $6 \% / y e a r$ decline periods.

For China, production was growing during the years prior to 2006 and, with the official reserves claimed in 2006, it looked reasonable to assume that production could increase by another few per cent to reach a plateau of around 4 mbd between 2010 and 2015 .

The actual production during the last 10 years in Russia, China and the Persian Gulf OPEC countries is in reasonable agreement with the production predicted by our model.

In comparison, the 2006 World Energy Outlook (WEO 2006) overestimated the production increase from the Persian Gulf region from 21 (2004) to $26 \mathrm{mbd}$ (2015) or about $2 \% / y e a r$ in comparison with the observed roughly $1 \% / y e a r$ growth rate. The IEA study correctly predicted the 2014 conventional oil production for Russia, but underestimated the possible production growth in China.

Some significant differences between our model prediction and the 2014 conventional oil production are observed for Africa and for the Americas. As has been discussed in the previous sections, the trends in Africa and South America were influenced by political and economic troubles, which led to a lower production than predicted by our "model", especially in Libya and other African countries. In contrast, and also influenced by the high oil prices, the exploitation of known oil fields in North and South America was seen during this period and resulted in a delay of the decline trend. But not even the high oil prices could stop the steep decline of oil production in Mexico.

One might conclude that our model's predictions of 2010-2015 production, using production data from 2000 to 2005 , were not only in reasonably good agreement with the actual regional and global conventional oil production trends observed during this period, but resulted in somewhat better predictions than the economic- and resourcebased models did. But obviously, the real test for the predictive power of different forecasting models will be the comparison with the real production during the next 5-10 years.

\section{A Comparison with Other 2015 Models}

This section is concluded with a comparison of our model's forecast for the years 2020, 2030 and 2050 with the resource-based forecast from Laherrère in April $2015^{21}$ and

\footnotetext{
$\overline{21}$ The numbers from J. Laherrère May 2015 report http://aspofrance. viabloga.com/files/JL_Hubbertlineraization24May are taken from obtained from the Figure 98 (page 56).
} 
with the November 2015 IEA WEO 2015 (which includes predictions only through 2040).

Starting from a conventional oil production of about $71 \mathrm{mbd}$ in 2014 and combining our modelled results from the different regions, this model predicts that the upper production limit will decline to $66 \mathrm{mbd}$ in $2020,50 \mathrm{mbd}$ in 2030 and $33 \mathrm{mbd}$ in 2050. Adding all unconventional oil and oil-equivalent liquids, and including the 2014 refinery gains of about $2.5 \mathrm{mbd}$, the resulting upper production limit for all liquids is about $93.5 \mathrm{mbd}$ (2015) from where it declines to 92.5 (2020), $79.5 \mathrm{mbd}$ in 2030 and to less than $62 \mathrm{mbd}$ in 2050 .

The forecasting method from J. Laherrère is based on the Hubbert production profiles and the best available maximal crude oil reserve data. Laherrère predicts a global conventional crude oil peak at about $73 \mathrm{mbd}$ around 2015-2018. His estimates for 2020, 2030 and 2050 are about 72, 65 and $35 \mathrm{mbd}$, respectively.

When including all unconventional oil and oil-equivalent liquids, Laherrère predicts a global production peak for all liquids (including refinery gains) around the year 2020 at approximately $94 \mathrm{mbd}$. This is followed by a decline to about $88 \mathrm{mbd}$ in 2030 and $60 \mathrm{mbd}$ around 2050.

The forecast from our model agrees with the calculation from Laherrère with respect to the predicted possible production maximum and regarding the production around the year 2050. However, for the years 2020 and 2030 Laherrère's production estimates are between 10 and $20 \%$ higher than ours. The difference seems to originate primarily from Laherrère's forecast of an increased production in the Persian Gulf OPEC countries during the next decades compared to our forecast of a rather flat production.

It is interesting to compare those two approaches with the economic-based forecast from the WEO 2015. Unfortunately, the definitions from the IEA and the EIA data (used as input for our model) for the various types of oil and oil-equivalent liquids are slightly different and the production numbers can differ by a few per cent. To provide a better basis for the comparison between the different models, the IEA production numbers for the different years are multiplied by the ratio of the 2014 EIA and IEA production data. In contrast to the resourceconstraint production models, the IEA2015 forecasts a rather constant conventional oil global production for the next several decades. Oddly, this forecast of a relatively constant level of production assumes a declining production of about $3.9 \% / y e a r$, significantly smaller than their own estimated $6 \%$ average decline rate (WEO 2013), from existing fields combined with further exploitation of "known" fields, exploitation of "yet to be developed" fields and-especially-exploitation of "yet to be discovered fields".
Taking only the forecasts for the existing fields and the further exploitation of the "known" fields, the IEA prediction for conventional oil would thus be about $70 \mathrm{mbd}$ in 2020, $62 \mathrm{mbd}$ in 2030 and $52 \mathrm{mbd}$ in 2040 and thus much closer to the resource-based forecasts.

The striking difference between the IEA's predictions and the resource-based predictions is obvious. And it seems that those who take the resource-based models seriously should not only prepare for oil price volatility but should also prepare for changes in both the ratio of conventional oil to other petro-liquids and for increasing importance of the oil coming from the Persian Gulf OPEC countries and how this oil might be distributed around the planet. Some ideas about near-term regional oil supply constraints will be discussed in the next section, and more details about the regional oil supply situation will be presented in a subsequent paper (part II of this analysis).

\section{Near-Term Consequences for the Large Oil Importers}

\section{Oil-Exporting Regions Important to Western Europe}

Crude oil extraction in Western Europe declined from $6.2 \mathrm{mbd}$ in the year 2002 to less than $2.87 \mathrm{mbd}$ during 2014. It is interesting to note that this decline was only partially compensated with increasing imports, as the oil consumption in Western Europe was about $13 \mathrm{mbd}$ in 2014, 2.5 mbd less than in the year 2004.

With the very limited remaining reserves, it is rarely disputed that European oil production will continue its decline during the next decades. Following this model, it is expected that by 2020 only about $1.9 \mathrm{mbd}$ will be produced in Western Europe. During 2014 Western Europe had a net import of about $6 \mathrm{mbd}$, dominantly through pipelines, from the FSU countries, Russia, Kazakhstan and Azerbaijan, about $2.1 \mathrm{mbd}$ came from the Persian Gulf OPEC countries and $2.1 \mathrm{mbd}$ from Africa. According to the IEA 2014 Medium-Term Oil Market report, ${ }^{22}$ the IEA expects that the imports from these countries will drop by about $1 \mathrm{mbd}$ $(10 \%)$ during the next 5 years. In contrast, when following our modelled production declines, it can be expected that the total imports from the FSU countries will drop from $6 \mathrm{mbd}$ today to about $4 \mathrm{mbd}$ in 2020. Combining this modelled production decline estimates for Western Europe and the FSU countries, one expects that the oil

\footnotetext{
${ }^{22}$ See the IEA oil market reports at https://www.iea.org/oilmarketre port/omrpublic/ and expected oil export/import flow in 2019/2013 at https://www.iea.org/oilmarketreport/2014_06_18_Oslo_MTOMR\% 202014.
} 
consumption in Western Europe around the year 2020 will be about $3 \mathrm{mbd}$ (between 20 and $25 \%$ smaller than in 2014).

\section{Oil-Exporting Regions Relevant for the USA}

During 2014, about $19 \mathrm{mbd}$ of oil, about $10 \%$ less than before the 2008 crisis year, was consumed in the USA. According to the 2015 BP report, the net imports in 2014 were about $5.3 \mathrm{mbd}$ of oil and oil-equivalent liquids. About 2.6 and 0.3 mbd came from the direct neighbours Canada and Mexico, respectively. The remaining net imports came from the Middle East $(1.8 \mathrm{mbd})$, from South and Central America $(0.3 \mathrm{mbd})$ and from Africa $(0.3 \mathrm{mbd})$. Assuming that the internal consumption in these regions remains roughly at today's numbers, the expected net imports from South America, Mexico and from Africa into the USA, about $1 \mathrm{mbd}$, will be terminated during the next 5-10 years.

\section{Oil-Exporting Regions Relevant for the Asian Pacific Countries}

Japan, South Korea and Singapore are highly industrialised countries without domestic oil production. Their relatively high per capita oil consumption is thus $100 \%$ imported. About $80 \%$ of this oil, $6.5 \mathrm{mbd}$, comes from the Middle East. In contrast to Japan, where the oil consumption decreased during the last 10 years by $0.9 \mathrm{mbd}$, the consumption in South Korea and Singapore is increased by 0.2 and $0.5 \mathrm{mbd}$, respectively.

The other large oil importers are China and India. In 2014, China produced about $4.2 \mathrm{mbd}$ of oil and had a net oil (and oil-equivalent liquids) import of about $7.1 \mathrm{mbd}$. The oil was mainly imported from the Persian Gulf OPEC countries (3.5 mbd), from Russia and Kazakhstan (0.9 mbd), from West Africa $(1.2 \mathrm{mbd})$ and from South America $(0.75 \mathrm{mbd})$. India imported about $4 \mathrm{mbd}$, about $80 \%$ of the consumer oil. This oil came dominantly from the Middle East $(2.4 \mathrm{mbd})$, West Africa $(0.6 \mathrm{mbd})$ and South America (0.7 mbd).

According to the BP 2015 report, in 2014 the remaining Asian Pacific countries imported another $4.8 \mathrm{mbd}$ from the Middle East countries. Thus, the Asian Pacific region as a whole imports more than $17 \mathrm{mbd}$ from the oil-rich Middle East countries. According to the IEA estimates, by 2020 the imports from this region will further increase by $0.8 \mathrm{mbd}$. According to our estimate ("The Persian Gulf OPEC Countries" section), and without war-like disruptions, a rather constant oil production in the OPEC Middle East countries and for the next decades is expected. However, as the oil production in Africa is modelled to start its decline during the next years, one should expect a steep decline of the oil exports from Africa.

\section{Summary}

In this paper, I have presented a new approach to model the future oil production in different regions of the planet. This new approach is based on the regional conventional and unconventional oil production trends observed during the past few years.

Following the well-documented oil production decline in Western Europe, Indonesia and Mexico during the past decade, it was found that the observed oil production decline in these regions can be described with a very simple function. Once no significant new fields will be added to the production, the production stops growing and a plateau production might be maintained for several years. The length of the possible plateau production period depends on several factors, including the ability to export the additional oil from yet unexplored fields under profitable conditions. However, for regions which have increased the production rapidly, it is expected that the plateau production can be maintained only for about 5 years. Afterwards, the production declines by about $3 \% /$ year for a period of 5 years and followed by the terminal decline of $6 \% /$ year.

Applying this model for all oil-producing regions of the planet, a forecast for the future regional oil supply is obtained. For the Middle East OPEC countries, it might be possible maintain their current production during the next decades. For all other regions, the oil production is predicted to start its terminal decline during the next few years. Knowing that in particular the global ocean-based transport system is constrained by the geography of the planet, it appears realistic that people in countries without significant domestic oil reserves, such as many countries in Western Europe and Japan, will be confronted with the unavoidable declining oil availability and thus a less "oil". based way of life during the next years.

Acknowledgments While the ideas presented are from the author alone, my thanks go to my friends, colleagues and many students who have helped me during extensive exchanges to formulate these points and arguments. In particular, I would like to thank W. Tamblyn for the critical and careful reading of the manuscript and for many suggestions on how to improve the clarity of the presented ideas.

\section{References}

For a detailed analysis about the future oil production possibilities in Russia and Eastern Siberia

Campbell C, Laherrère J (1998) Scientific America 1998, the article can be found here http://www.scientificamerican.com/article/theend-of-cheap-oil/

Campbell C (2015) Vol 1, No 4 Oct. 2015, page 81; "The Oil Age" journal from the Petroleum Analysis Centre, Editor Dr. Roger Bentley 
Hubbert MK (1956) The original publication can be found at http:// www2.energybulletin.net/node/13630. More informations about the scientific contributions of M.K. Hubbert and further references can be found in the Wikipedia article https://en.wikipedia. org/wiki/M._King_Hubbert

Mushalik M (2015) Vol 1, No 2 April 2015, page 87, chart 1; "The Oil Age" journal from the Petroleum Analysis Centre, Editor Dr. Roger UpdateBentley
Tverberg G (2016) has written extensively about the relation between the global economy and the future oil production and the latest articles can be found at http://ourfiniteworld.com 